\title{
What I've Learned about Revising a Dissertation
}

\section{JAMES MULHOLLAND}

The structural changes in higher education and scholarly publishing have raised new questions about the usefulness of the dissertation as precursor to scholarly publication. This essay reconsiders the process of turning a dissertation into a book manuscript. Recent manuals about dissertation writing like From Dissertation to Book and Revising Your Dissertation are helpful but often provide overly broad conceptualizations about how to assess a dissertation and revise it into a book. Likewise, academics tend to describe the revision process in conceptual terms by focusing on too impressionistic ways of distinguishing the difference between a dissertation and a book. In addition, they spend surprisingly little time discussing the methods and techniques of writing and revision that authors actually use. Drawing from my own recent experience as an example, I offer practical advice as well as theoretical reflections on the research and writing process by which dissertations can become book manuscripts.

Keywords: academic writing and revision, authorship, scholarly publishing and publishers

In 2009 I was asked to give a one-hour question-and-answer session about how I had revised my dissertation to the students in an Emory University graduate course called 'Scholarly Publishing Today.' The course was taught by Amy Benson Brown, who heads Emory's Author Development Program, which is meant to provide guidance for academics about the revision and publishing process. She invited me to speak to her class because I was an English professor from a small liberal-arts college who had spent the year at Emory's Fox Center for Humanistic Inquiry revising my manuscript for publication. This manuscript was based on a dissertation I had completed in 2005. She felt I was in an ideal position to speak with students who were at an earlier phase in their career about how to turn a dissertation into a book. 
Throughout my presentation, I linked conceptual concerns to my specific writing habits and techniques because I believe that academics need to converse more openly about exactly how we write and revise. Academics are supremely talented at discussing the conceptual aims of writing a book while spending relatively little time discussing the practical methods by which we might achieve those conceptual goals. It is important to talk about how to structure arguments, how audiences might respond, which previous scholarship can best advance debates, and what serious questions are at stake in critical writing. But I have found that academics (except for creative writers) spend little time talking about the actual process by which words are made into sentences and sentences are organized into arguments. We seem to skip these details, perhaps perceiving them as shamefully personal or unworthy of debate. I'm always surprised when I realize I know more about my students' writing processes than some of my closest friends'.

This doesn't mean that academics and publishers don't discuss writing or, more specifically, revising dissertations. There are many well-known books that address these concerns. (The ones I know best are William Germano's From Dissertation to Book and Beth Luey's edited collection, Revising Your Dissertation.) Most of these books, however, seem to emphasize conceptual questions in their effort to be widely applicable. They suggest that revising a dissertation requires identifying what's important about one's research and broadening the audience so that a manuscript is more attractive to publishers. These revisions, Germano explains, necessitate 'expanding the population of readers so that it becomes broad enough for a publisher to take your manuscript and turn it into a book.' ${ }^{1}$ To accomplish this, he advises that scholars find 'within the thesis [of their dissertation] ... what can be of value to a broader readership.' ${ }^{2}$ Scott Norton, an editor at University of California Press, likewise suggests that prospective authors should rewrite so that their dissertation can 'make a larger statement with more examples and a thesis that will cover more ground.'

This is solid and instructive advice. Both of these editors helpfully lay out how to conceive of the revision process, and they provide invaluable examples from their experience with publishing houses. But my reaction to this kind of advice was that of an academic, not an editor; I always wondered, 'How?' I knew I was supposed to write a well-researched manuscript that addressed significant scholarly questions clearly and 
precisely while attracting as large an audience as possible. But how do I do that? What choices should I make to achieve these goals? And what happens when these demands seem to be in conflict-for example, when the need for argumentative rigour limits or even forecloses my attempts to broaden the scope and appeal of my writing?

Answers to these questions are difficult to produce, of course, because they can depend entirely on the field. While there may be a 'recipe' for a dissertation, Germano notes, there is no 'formula' for writing an academic book. ${ }^{4}$ Therefore, in this article, I want to offer my own experience revising my dissertation as an example of practical solutions to these conceptual questions. My testimony is not meant to be prescriptive or to suggest that I have discovered a secret no one else knows. I offer my story because opinions about how to write a book are contradictory. I never found unanimous agreement about what is the best strategy to revise a dissertation. My reaction to the differing advice was to aggregate as many opinions as I could from as many sources as possible. Only then did I determine how I wanted to proceed with my revisions. Therefore, I hope my description will be yet another example that future authors might consider as they formulate their own plans. As my Fox Center colleague, the historian Ranaan Rein, regularly reminded me, 'There are many ways to write a book.' Here's how I did it.

\section{GETTING AWAY / FINDING NEW ROUTINES}

My first piece of advice was a pitch for attending a humanities centre, acquiring a fellowship, or in some other way securing time and space away from familiar routines. For me, this time and space was crucial because revising a dissertation requires determination and consistency. To produce this consistency, I needed to escape from institutional obligations and had to remove myself from my well-known terrain. I am a diligent and self-motivated writer, so at first I worried that moving away from home for a year would disrupt my momentum. In fact, the opposite happened. Being away from familiar routines focused me on my work - I knew few people in my new city (Atlanta) and had few social obligations. This made it easier to spend hours in my office writing, and the newness of the place seemed to put my project in perspective. There are obviously many different ways to achieve new perspectives, and a residential fellowship is only one of them. But any change in 
surroundings - whether it's moving away or altering daily habits helps the writer reconsider a project, jumpstart revisions, or conclude those final chapters. My revisions were completed only by the persistent application of effort. For me, writing a book necessitated perseverance and dedication as much as inspiration and intellect.

\section{DON'T WRITE LONELY}

If there is one thing that I would say was essential to revising my dissertation, it was having multiple readers whom I could trust. Don't write lonely - this was one of the most important lessons I had to learn in graduate school. When, as an undergraduate, I was counselled about graduate training, I was told that the labour of an academic is solitary. This needn't be the case. In fact, the best academic work is highly social. As a graduate student, I was a member of a dissertation-writing group with three other friends (a group that continues to this day). I vetted my scholarship with a faculty writing group at my home institution, Wheaton College. And while at the Fox Center, I worked on my book in tandem with another external fellow, Benjamin Kahan, a queer theorist teaching at Louisiana State University. We shared ideas, exchanged work, rethought individual sentences together. These new readers reframed already-settled ideas and encouraged me to maintain my momentum. The combination of being away from familiar surroundings, focusing exclusively on my writing, and adding new readers meant that my year at Emory was the most productive of my life; therefore, I encouraged everyone to seek out new readers as often as possible.

Still, these readers must be people who can be trusted with weighty decisions. I found toward the end of my project that crucial theoretical, conceptual, and structural decisions-ones that I had been putting off-needed to be made. I had difficulty seeing how these choices (Should I cut the first chapter? Should I divide the book into two parts? Should my introduction be historical?) made a difference for my overall argument. Talking through the possibilities with trusted readers clarified the options. There were many times when I was indecisive about my project. At those moments, the judgement of my friends about my project was invariably more lucid than my own.

It was also important for some of these trusted readers to come from outside of my own field. I had numerous readers who were trained primarily in twentieth-century literature, film, contemporary theory, 
psychology, Hispanic studies, and art history, even though my manuscript dealt with eighteenth-century British literature. At first I felt this was to my detriment. But soon I found that though responses from readers within my field were important, readers outside of my field had distinct advantages. First, they required me to explain clearly the historical references and scholarly stakes of my writing; it was never self-evident to them why certain ideas mattered the way I assumed they did. Second, I was able to adapt the methods and scholarship of these other readers to my own questions. This was a helpful way for me to dislodge myself from the settled orthodoxies of my field and expand the scope and imagination of my arguments. In my discussions with editors, it has regularly been impressed upon me that academic presses (maybe all presses) look for books that exhibit new attitudes and propose new ideas. Readers from other fields offered an immediate way for me to shape these new ideas by adapting the most interesting concepts and methods from fields other than my own.

\section{CONTROLLED EVOLUTION: THREE ELEMENTS TO CONSIDER}

WHEN REWRITING A DISSERTATION

The process of composing a book, from its pre-dissertation phase to its final manuscript, was a 'controlled evolution.' I recognized that throughout my revisions my project had to mature continually, but I also realized that I needed to control how this maturation happened. I found that there were three elements that I needed to consider to manage this evolution. The first was having a sense of a time line; the second was understanding the scope of the manuscript's archive of primary and secondary sources; the third was being able to offer generalizations about the topic that were portable to other scholars' writing and usable within the wider field. These three elements could be thought of as broadly sequential steps in the revision of a dissertation.

\section{Establishing Time lines}

It was crucial to know when I wanted tasks to be accomplished and to adhere to this schedule. My time line had parallel tracks: I created a highly speculative master time line (that charted my progress over the course of years) before creating more detailed individual time lines for specific chapters. All of these deadlines - whether measured in weeks or years - were important markers because they constrained the amount 
of revision and forced me to make choices about the project without too much second-guessing. During revision it was easy to hesitate, doubleback, and get lost in the sense that more research or another draft would always improve my writing. Time lines yanked me away from this impulse.

Another advantage of establishing time lines was that they offered a barometer for understanding when the goals of my revisions had been met. As I began to revise my dissertation in earnest, I wondered how I would know when my revisions were complete. My friends and colleagues advised that I would know when my manuscript 'sounded right' or when it 'looked like a book.' Although they were frustratingly vague, I think these sentiments represent the often impressionistic standard that we use during the revision process. Perhaps this is unavoidable; each project is unique and thus has its own standard of coherence and completion. Yet my manuscript, like many others, ultimately is going to be judged not by my standards but by those of other scholars. As I revised, I tried to remain attentive to those characteristics of my writing and thinking that indicated my manuscript was ready for a wider public.

The most significant characteristic I noticed involved the law of diminishing returns. Some scholars suggest that revision always makes writing better. I disagree. There is a point when revision makes writing worse or, more likely, when revision makes writing neither better nor worse but simply different. I stopped revising when I was picking among two equally interesting and viable directions, neither of which was changing appreciably the theoretical importance of my argument. In other words, I stopped making changes when those changes seemed to be for their own sake rather than a means of making the argument better. In the later stages of my revisions, I was rewriting perfectly good sentences because they felt old and stale. Of course, they seemed that way to me because I'd been living with them for years. They didn't seem old and stale to other readers. This was the moment when I realized I was revising out of an emotional need rather than an intellectual one. I was rewriting because it was my habit, because revision is what authors do. Likewise, when the manuscript's argument seemed relatively stable despite the changes I was making, I knew that I was almost done with my manuscript and needed to seek the judgment of a wider audience that I didn't already know. 
There was a corollary to this notion that my revisions were complete when they produced little in return: A stable and consistent argument also meant that small changes led to vast improvements in clarity. As I got closer to completing my manuscript, I found that I could accomplish a lot by accenting a word, repeating an earlier phrase, or adding a single sentence. Toward the end of my project, most of my revisions did not require large amounts of research or rewriting but rather a renewed attention to tightening the connections between the ideas already in my work. Increasingly, the answers to my questions about how to revise were inside my manuscript rather than outside of it, and sticking to a time line forced me to recognize this important shift.

\section{Understanding the Scope of Scholarly Evidence}

The second element of this controlled revision concerned the scholarly material itself. Once my time line was established, I had to consider what I wanted the book to encompass that wasn't already included in the dissertation. I also needed to decide what materials needed to be removed. Determining the scope and type of material included in my manuscript was an ongoing process. It was worrisome and anxious but also a key part of distinguishing my manuscript from my dissertation.

Everyone seems to agree that a successful academic book must expand the archive of its dissertation. I considered this extensively as I began my revisions. ${ }^{5}$ My dissertation contained five chapters largely organized around single authors each of whom represented an aspect of a single literary theme spread across a century-long historical period. This was a fairly standard structure for a literature dissertation, and even at the time of its writing, I knew that I would need to alter it if I wanted to publish a book. My solution was to enrich the contents of my archive, which meant including more contextualizing details, inserting new authors, and widening the scope of the topics under investigation. I consciously searched for more imaginative details and interesting anecdotes in my materials. I sought out ways to include illustrations to break up what I perceived to be the monotony of text. Structurally, I reorganized my single-author-focused dissertation chapters into book chapters that were driven by multiple authors.

Expanding my archive and achieving this richness occupied the first two years of my revisions. Ultimately, I kept only two of my dissertation's five chapters. These two chapters were my strongest because they 
isolated most effectively the topic I wanted to understand. These also contained the most interesting evidence and the most provocative readings. In the course of revising, I had to build an entirely new framework and archive around these two chapters. I travelled to collections in Britain, searched through primary-source databases, and moved away from literary criticism in favour of a historicized cultural theory. I discovered authors new to me and integrated them into the project, surrounding them with cultural details I had not known as a graduate student.

This period of expanding the archive was followed by two years of contraction during which I cut much of the archival material that I had recently collected. Even though some of the research I had undertaken after finishing my dissertation never made it into my manuscript, I still think of this research as useful. I see there is a greater variety of authors and texts in my book manuscript than my dissertation. I distinctly remember as a graduate student wondering how the authors of those scholarly books that I admired had achieved their enormous range of cultural reference. Their footnotes and endnotes were intimidating. Now I realize that these books weren't created by researchers who were necessarily more skilled than me, but by authors who had devoted time to this process of growing and fitting the archive to the book's argument.

\section{Generalizing and Portability}

This process of expanding and then trimming was an essential part of revising my dissertation because it allowed me to make more confident assertions about my topic. The expertise that made my manuscript look intellectually richer and 'sound' more confident than my dissertation came from an ability to convey general conclusions about my topic. In my admittedly limited experience, academic publishing is driven by this desire for newness - of topic, of method, of materials. The need for a clear articulation of profound scholarly stakes seems to be more crucial than ever for an author to have success with publishers, constrained as they are by large numbers of submissions, shrinking budgets, and falling sales. In this publishing climate, settled knowledge need not be rehearsed again. Broad, aggressive articulations of the project's significance are the most important portions of a manuscript. If in doubt, be bold.

When I began my revisions, I was not bold. As a graduate student I, like many others, trained myself to be precise and focused. I hesitated, especially with others' scholarship, afraid to overstate my interpretations 
of their work. My tendency was to minimize rather than maximize the significance of my arguments in a misguided effort to focus narrowly on indisputable claims. Always careful, I intentionally shortened the horizon of my dissertation. These skills were crucial to learn, but they interrupted my ability to intervene broadly within my field.

It was extremely difficult and time-consuming for me to overcome this hesitancy and realize that great scholarship ignites controversy and debate as much as it consolidates unanimity of opinion. But the effect of this slow conceptual reorientation was an increased attention to generalization in order to establish how my manuscript answered questions and began debates that other readers cared about. I achieved this by writing a select number of sentences that were portable. As I revised my book, I was more keenly aware than ever about how others might use my writing to advance their own ideas. And as I wrote, I sought to create sentences that were succinct and easily citable by other authors. It took years for me to develop this skill. But it came from adjusting my relationship to other scholars. When I noticed that most of the sentences from other scholars that had survived my revision process were those broad, expansive formulations of their overall argument, I began to develop my own versions of these types of sentences. I returned to conference abstracts, grant proposals, and job materials, looking for concise descriptions of my project's goals. I revised these sentences by attempting to anticipate how they might aid future scholars. I tried to imagine what I would cite if I was quoting from my book.

This ability to generalize and to craft portable sentences was what distinguished my book manuscript from my dissertation. My dissertation, by design, required me to demonstrate my mastery of a specific discipline and a field. My book, however, needed to advance the field, pushing those boundaries that my dissertation had sketched out. I found scholarly monographs that I wanted to emulate, using their structures as a model and imitating their patterns. Even though I had read such material with great attention before, I had never been so keenly aware of the mechanics - the joints, fissures, and beams - by which a book was put together. And when I didn't know how to proceed in my revisions, I stole. Uncertain of what distinguished a book from a dissertation, I lifted the frameworks from other scholarly books I admired as a starting point for my own revisions. I meditated on these books' tables 
of contents, which were a superb guide to chapter length and organization. I examined the type of materials included and how other authors transitioned between individual sections. I personalized these transplanted frameworks, bending them to my own archive and arguments. By the time the revisions were completed, my framework bore only a slight resemblance to these earlier models, but they were essential to getting underway.

Another strategy to distinguish my manuscript from my dissertation involved simply cutting out the majority of the criticism that I had included in my dissertation and replacing it with my own generalizations. However, I soon found that this blunt procedure was ineffective. The number of sentences devoted to other scholars was a useful but ultimately too-crude indicator of how I related to the important claims in my field. Instead, I needed to absorb and subordinate other scholars rather than cut them out. In practical terms, I forced myself whenever possible to condense a paragraph of scholarly descriptions into one or two sentences. I became more comfortable with relating scholars' ideas to my arguments rather than just worrying about whether I had faithfully represented them. By spending less space on explaining their positions, I devoted more time to making them serve my claims. And by constraining the amount of space I could devote to individual scholars, I became ferociously selective about what was truly needed for me to make my arguments. In some ways, this was absorptive, arrogant, and fundamentally solipsistic. I had to learn how to write as if my own research were both at the leading edge and the centre of the discipline all at once.

\section{THE MECHANICS OF WRITING AND REVISING}

Revising my dissertation was fundamentally an organizational problem: I had to decide how to manage and make accessible a huge amount of expert information. In the process of writing my manuscript, I modified every aspect of my research, from reading, to note-taking, to the actual exposition. I began my dissertation by taking notes on three-by-five-inch index cards. Each card had a quotation or a single relevant piece of information that I had encountered in the course of my reading. I learned this system from my dissertation director, who used it as well. Like him, I collected these note cards in shoeboxes; one box was devoted to each chapter. I composed my first dissertation chapter by organizing 
(and reorganizing) over five hundred index cards that I had collected. The overall argument was formed by the order of ideas on the note cards. Reading from the first to the last card was designed to repeat the structure of the chapter.

This system failed. While it made my writing seem tactile and mobile, it was also enormously cumbersome. I quickly modified this system by recording all of my notes in Microsoft Word documents: One computer file was devoted to each scholarly source or primary text, and I took notes as I read. This process was slow and required me to be vigilant about my note-taking. It also produced a vast amount of material; since I didn't have a firm sense of my argument yet, I didn't know what might be relevant. So I wrote down nearly everything. Even when I understood my project better, my note-taking remained horribly inefficient. Now I simply think of it as a necessary investment of time. But the copious amount of pre-writing had one advantage in that I began to interact closely with the material, constructing sentences and producing interpretations as I read.

When I felt I had finished researching for a chapter-a feeling usually brought on more by impatience than by an intellectual decision-I composed the chapter. I began by pasting all of my notes into a single computer file, which often ran to seventy or eighty single-spaced pages. Then I deleted any sentences and ideas that didn't seem relevant. By eliminating those notes that felt extraneous and reorganizing those that remained, I applied some initial shape and direction to my chapter. This was a time-consuming process, but it gave me the feeling that I had weighed and considered every piece of evidence and only the best material had survived.

After I had completed my deletions, I arranged the remaining notes within topical sections, which I would title with sub-headings that were often single keywords or an author's name. I didn't attempt to rewrite, instead opting to allow associations to form an initial draft of my argument. I then untangled the mess of my somewhat-organized notes by rewriting each individual section. I typically began with the sections that made up the body of the chapter - the individual readings of primary sources - rather than with the chapter's overall framework. In other words, I tended to write from the inside out, from the middle outward to the tail ends - the introduction and conclusion - of each chapter. Only when the individual sections were coherent did I consider 
the chapter as a whole document and attempt to integrate all of its individual sections. This last step required paying attention to language by polishing and smoothing the sentences until they were readable.

This process of categorizing, reorganizing, and joining was informed by the ways that I interfaced with my writing. I wrote both on a laptop and a desktop computer but found the wide screen of a desktop to be far superior to my laptop's. This was because when I wrote I formatted my text into single-space, 10-point type with the view setting reduced to 60 or 70 percent. This allowed me to increase the amount of text that I could see on the screen. I wrote with pages and sections in mind as much as individual words and sentences. This structural approach seemed natural to me but differed enormously from those of some of my friends. Kahan, my colleague from Emory, wrote all of his documents with the text doubled in size (200 per cent view) - seemingly a big-print version of his project. I imagine that he liked this view because he could deliberate on individual words. Fascinatingly, he tended to write short chapters with long, theoretically rich sentences. I composed lengthy chapters with short declarative statements. As I revised his work, I added material, broke up his longer sentences, and asked for more simplicity and clarity. As he revised mine, he cut out individual elementscalling them 'local colour' - and required me to elaborate on the theoretical import of my individual readings and historical details. Our argumentative styles, it seems, were heavily influenced by the way that we interacted with writing on the computer screen.

\section{CONCLUSIONS}

After five years of revising my dissertation, I've realized that I need to link these practical methods of writing - having an awareness of how I take notes, how I format text, how I write sentences, how I look at my words on the computer screen - with my more conceptual concerns about publishers' desires, audience demands, and academia's everchanging intellectual interests. It's not just the process of identifying these elements that matters but also instituting well-designed procedures for achieving conceptual aims. I realize now that how I composed my manuscript represents how I conceptualize the meaning of revision. I perceived my writing like objects to be parsed, divided, manipulated, and moved around. In fact, I saw my chapters as if they were composed of individual pieces of writing that were meant to be shifted around 
within a larger framework. This tactile, tangible model of writing was my way of organizing what seemed to be an overwhelming amount of scholarly material and an intimidating number of intellectual choices. How I wrote affected how I thought. When I write work in the future, I will alter my procedures as a way to tinker with my conceptualizations and thinking.

Yet I don't mean my example to be prescriptive. Evolving my research and writing processes, as well as linking my practical methods with the conceptual concerns that writers like Germano have outlined, was an essential part of successfully revising my dissertation. Being attuned to how personal and individual this process can be while also understanding how others accomplish their revisions might be the most important task for a young scholar faced with the daunting task of turning a dissertation into a book.

When I had completed my revisions, I realized that revising a dissertation doesn't make a book. The revision process led me to the point when I was able to seek out a wider audience by contacting publishers. As I'm now learning, this process goes on, with new demands, concepts, and techniques, when a manuscript begins the process of evaluation and production that makes it into a saleable book.

JAMES MUlholland is an assistant professor of English at Wheaton College, Massachusetts. His work has appeared in ELH, Oral Tradition, and Studies in Eighteenth-Century Culture. His project, Sounding Imperial: Poetic Voice and the Politics of Empire, 1730-1820, is under contract at Johns Hopkins University Press.

NOTES

1. William Germano, From Dissertation to Book (Chicago: University of Chicago Press 2005), 10

2. Ibid., From Dissertation to Book, 5

3. Beth Luey, ed. Revising Your Dissertation: Advice from Leading Editors (Berkeley: University of California Press 2002), 20

4. Germano, From Dissertation to Book, 13

5. Germano describes dissertation revisions as " "getting to more" - more clarity, more clearly defined purpose ... more potential readers' (8). 